\title{
CARDIOPROTECTIVE EFFECT OF INDIGOFERA TINCTORIA LINN. AGAINST MYOCARDIAL INFARCTION-INDUCED RATS
}

\author{
SHANKARAIAH P ${ }^{1 *}$, PRIYANKA K ${ }^{2}$ \\ ${ }^{1}$ Department of Pharmacy, Chaitanya College of Pharmacy Education and Research, Hanamkonda, Warangal, Telangana, India. \\ ${ }^{2}$ Department of Pharmacy, SRR College of Pharmaceutical Sciences, Volbhapur, Karimnagar, Telangana, India. \\ Email: drspuligilla@gmail.com
}

Received: 27 July 2017, Revised and Accepted: 27 September 2017

ABSTRACT

Objective: The aim and objective of the present study are to study the protective effects of ethanolic extract of Indica tinctoria (EEIT) in isoproterenolinduced acute myocardial infarction (AMI) in rats.

Methods: The effect of two doses of isoproterenol ( $5 \mathrm{mg} / \mathrm{kg}$ and $8.5 \mathrm{mg} / \mathrm{kg}$ body weight) changes in aspartate transaminase (AST), alanine transaminase (ALT), lactate dehydrogenase (LDH), creatine phosphokinase (CPK), and total protein (TP) and lipid hydroperoxides, superoxide dismutase (SOD), and glutathione (GSH) in blood serum and heart homogenate, for the two consecutive days (29 and 30), were administered subcutaneously in rats in pre-treatment with EEIT for the 28-day study.

Results: There was increased the AST, ALT, LDH, CPK, and lipid peroxides levels and decreased the TP, SOD, GSH with Isoproterenol-induced group. Pre-treatment for 28 days with Indigofera tinctoria significantly $(\mathrm{p}<0.05)$ increased antioxidants (SOD, GSH) , TP levels and decreased the cardiotoxic agents significantly $(\mathrm{p}<0.05)$ such as LPO, AST, ALT, LDH, and CPK levels in treatment groups.

Conclusion: I. tinctoria contains beneficial bioactive photochemicals that have been protective effective against isoproterenol-induced AMI in rats.

Keywords: Indigofera tinctoria, Cardiotoxic, Oxidative stress, Isoproterenol, Antioxidants.

(C) 2018 The Authors. Published by Innovare Academic Sciences Pvt Ltd. This is an open access article under the CC BY license (http://creativecommons. org/licenses/by/4. 0/) DOI: http://dx.doi.org/10.22159/ajpcr.2018.v11i1.21643

\section{INTRODUCTION}

Myocardial infarction (MI) or acute MI (AMI) was commonly known as a heart attack. It occurs when decrease the blood and oxygen supply to the cardiac muscle due to occlusion of a atherosclerotic plaque in coronary artery leads to the death of heart tissues [1]. The various mechanisms propose that the generation of free radicals has been implicated in the pathophysiology of AMI [2]. Isoproterenol is a betaadrenoceptor agonist that induces MI by causing imbalance between oxidants and antioxidants in the myocardium [3,4]. Several antioxidants have been producing the possible protective actions against AMI [5].

Medicinal plants play an important role in health-care systems as well as in international herbal and pharmaceuticals. The most important bioactive constituents of plants are alkaloids, tannins, flavonoids, and phenolic compounds that produce a definite antioxidant action against free radicals [6,7]. The plant Indigofera tinctoria known as Neeli in Tamil and belongs to the family Fabaceae which popularly found throughout India. The plant roots, stems, and leaves of I. tinctoria are bitter and used as thermogenic, laxative, trichogenous, expectorant, anthelmintic, gastropathy, splenomegaly, cardiopathy, hepatoprotective, anticancer, epilepsy, neuropathy, chronic bronchitis, and diuretic and also useful for promoting the growth of hair $[8,9]$. The present investigation of the cardioprotective effect of ethanolic extract of Indica tinctoria (EEIT) against isoproterenol-induced AMI in rats as preventive model was conducted.

\section{METHODS}

The male albino Wister rats were selected about 150-200 g and taken the approval of the Institutional Animal Ethics Committee of SRR college of Pharmaceutical sciences, Volbhapur, Karimnagar. Animals were divided into four groups; each group consists of 6 animals $(n=6)$ after. Group I animals served as control, received orally normal saline alone for 28 days. The Group II (Disease control) animals were received normal saline for 28 days. Group III and IV animals were pre-treated with EEIT Linn extract $(100 \mathrm{mg} / \mathrm{kg}$ and $200 \mathrm{mg} / \mathrm{kg}$ ) for 28 days, and on $29^{\text {th }}$ day and $30^{\text {th }}$ day, all three Groups (II-IV) were administered with isoproterenol hydrochloride at two different dose levels $(5 \mathrm{mg} / \mathrm{kg}$ and $8.5 \mathrm{mg} / \mathrm{kg}$ ) subcutaneously except control group. After 30 days of experimental period, the animals of groups were anesthetized with phenobarbitone sodium $(35 \mathrm{mg} / \mathrm{kg}$ ). Blood samples were withdrawn from the retro-orbital route for estimation of serum aspartate transaminase (AST), serum alanine transaminase (ALT), serum lactate dehydrogenase (LDH) [10], creatine phosphokinase (CPK), total protein (TP) [11], antioxidants levels such as superoxide dismutase (SOD) [12], reduced glutathione (GSH) [13], and thiobarbituric acid (TBRS) [14]. Animals were then sacrificed by cervical dislocation under anesthesia, and hearts of each rat were isolated and rinsed in ice-chilled saline. A known weight of heart tissue was homogenized in $5.0 \mathrm{ml}$ of $0.1 \mathrm{M}$ of tris-Hcl buffer $\left(\mathrm{P}^{\mathrm{H}} 7.4\right)$ solution. The homogenate was centrifuged, and the supernatant was used for the estimation of various biochemical parameters same as serum. Results are expressed as mean \pm SD. The difference between experimental groups was compared by one-way analysis of variance.

\section{RESULTS}

Serum samples and heart homogenates results show significant $(p<0.05)$ increase in AST, ALT, LDH, and CPK levels and decrease in TP levels in isoproterenol-treated Group II in comparision with control. Pretreated with $I$. tinctoria showed significantly $(\mathrm{p}<0.05)$ decrease in levels of serum marker enzymes AST, ALT, LDH, and CPK and increase TP levels in Groups III and IV when comparison with disease control Group II (Tables 1 and 2).

High doses of isoproterenol hydrochloride lead to increase the oxidative stress in the heart and serum which causes decreases in the antioxidant 
Table 1: Serum levels of AST, ALT, LDH, CPK and TP content in normal and treated groups

\begin{tabular}{llll}
\hline Groups/parameters & I (normal) & II (isoproterenol) & III (EEIT 100 mg/kg) \\
\hline AST(IU/L) & $26.83 \pm 1.778$ & $54.83 \pm 1.869^{*}$ & $51.17 \pm 1.400$ \\
ALT(IU/L) & $21.17 \pm 1.922$ & $62.00 \pm 2.477^{*}$ & $58.17 \pm 2.613^{*}$ \\
LDH(IU/L) & $38.00 \pm 1.807$ & $44.67 \pm 2.092^{*}$ & $40.67 \pm 1.926$ \\
CPK(IU/L) & $49.00 \pm 2.352$ & $60.83 \pm 2.688^{*}$ & $54.83 \pm 2.845$ \\
TP(g/dL) & $10.85 \pm 0.2790$ & $4.767 \pm 0.2124^{* *}$ & $30.33 \pm 1.764^{* *}$ \\
\hline
\end{tabular}

Data results were (mean \pm SD) compared significant $\left({ }^{*} p<0.05,{ }^{* *} p<0.01\right)$ between control and treated groups, AST: Aspartate transaminase, ALT: Alanine transaminase, LDH: Lactate dehydrogenase, CPK: Creatine phosphokinase, TP: Total protein

Table 2: Heart homogenate levels of AST, ALT, LDH, CPK, and TP content in normal and treated groups

\begin{tabular}{llll}
\hline Groups/parameters & I (normal) & II (isoproterenol) & III (EEIT 100 mg/kg) \\
\hline AST(IU/L) & $29.00 \pm 1.366$ & $47.00 \pm 0.7303^{* *}$ & $42.00 \pm 0.894$ \\
ALT(IU/L) & $25 \pm 1.366$ & $55.00 \pm 08944^{* *}$ & $40.50 \pm 3.585^{*}$ \\
LDH(IU/L) & $35.00 \pm 1.826$ & $45.00 \pm 1.291^{*}$ & $40.83 \pm 1.276^{*}$ \\
CPK(IU/L) & $50.00 \pm 1.291$ & $58.67 \pm 1.406$ & $53.33 \pm 0.8433$ \\
TP(g/dL) & $9.800 \pm 0.6202$ & $9.283 \pm 0.5173$ & $9.6 \pm 0.5053^{*}$ \\
\hline
\end{tabular}

Data results were (mean \pm SD) compared significant $\left({ }^{*} \mathrm{p}<0.05,{ }^{* *} \mathrm{p}<0.01\right)$ between control and treated groups. AST: Aspartate transaminase, ALT: Alanine transaminase, LDH: Lactate dehydrogenase, CPK: Creatine phosphokinase, TP: Total protein

Table 3: Heart homogenate content of SOD, GSH, and TBRS in normal and treated groups

\begin{tabular}{llll}
\hline Groups/parameters & I (normal) & II (isoproterenol) & III (EEIT 100 mg/kg) \\
\hline SOD(units/mg) & $2.767 \pm 0.0954$ & $1.850 \pm 0.1176^{*}$ & $1.700 \pm 0.1751^{*}$ \\
GSH(nmoles/100 g tissue) & $3.033 \pm 0.1174$ & $1.133 \pm 0.1282^{*}$ & $2.083 \pm 0.1195^{*}$ \\
TBRS(nmoles/100 g tissue) & $0.9500 \pm 0.099116$ & $1.517 \pm 0.1424^{*}$ & $1.017 \pm 0.1108$ \\
\hline
\end{tabular}

Data results were (mean \pm SD) compared significant $\left({ }^{*} \mathrm{p}<0.05,{ }^{* *} \mathrm{p}<0.01\right)$ between control and treated groups. SOD: Superoxide dismutase, GSH: Glutathione

levels. Pre-treatment with I. tinctoria leads to the increase in the antioxidant levels in the heart compared with Group II. Isoproterenol showed decreased levels of antioxidants such as SOD and GSH and increased levels of TBRS when compared with Groups control, III, and IV which were pretreated with I. tinctoria and decreased levels of TBRS. The antioxidant property of I. tinctoria was shown in Table 3.

\section{DISCUSSION}

Isoproterenol (ISO) is a synthetic catecholamine, $\beta$-adrenoreceptor agonist and has been producing MI in large doses [15]. The formation of free radicals as well as lipid peroxides, which causes to damage the myocardial muscles $[16,17]$. The myocardium contains the LDH and transaminases as enzymatic markers of MI, which were releases from damaged tissues into extracellular fluid [18]. The results of phytochemical screening of EEIT contain the flavonoids, saponins, tannins, and phenols. The phenols and flavonoids were possess the potent antioxidant properties [19].

In the present study, the transaminases (ALT and AST), LDH, CPK, and TP serve as sensitive indicators in the severity of MI [20]. Isoproterenolinduced group increased the cardiac markers such as AST, ALT, LDH, and $\mathrm{CPK}$, and it may be due to the myocardium necrosis and decrease in the level of TP in serum as compared with control group. The alteration levels will be more in serum when compared to the heart homogenate.

Pre-treatment with Ethanolic extract of Indica tinctoria (EEIT) significantly $(\mathrm{p}<0.05)$ decreased the elevated cardiotoxic effects of large doses of Isoproterenol in rats. The contents of EEIT scavenging the free radicals, lipid peroxides, and increases the antioxidant enzymes such as SOD and GSH are the first line of cellular defenses of cell functionality and viability in cardioprotection. Depletion of GSH results in increased lipid peroxidation which can cause increased GSH consumption develops the number of chronic diseases such as cancer, neurodegenerative, and cardiovascular diseases [21,22]. Pre-treatment with EEIT significantly increased the antioxidant levels when compared with isoproterenol-treated groups. These results may indicate the
I. tinctoria Linn which is a beneficial as protective agent against MI induced by isoproterenol in albino Wistar rats due to its antioxidant and free radical scavenger properties.

\section{CONCLUSION}

The results of the present study conclude that EEIT elicited cardioprotective effect when given against isoproterenol-induced myocardial necrosis in albino Wistar rats. EEIT contains the beneficial phytochemicals such as flavonoids, saponins, and tannins. Phenols have cardioprotective property by decreasing the levels of serum aminotransferase, aspartate transferase, $\mathrm{LDH}, \mathrm{CPK}$, and thiobarbituric acid and increasing the antioxidant enzymes such as SOD, reduced GSH, and GSH peroxidase. Further studies are recommended to elucidate the mechanisms of the cardioprotective action of these plant active agents.

\section{ACKNOWLEDGMENT}

The authors are thankful to Principal, SRR college of Pharmaceutical Sciences, Volbhapur, Karimnagar Dist, for providing with all the facilities required in this work.

\section{REFERENCES}

1. Bansal R, Desai K, Gupta A, Banasal M. Text Book of Pathophysiology. $1^{\text {st }}$ ed., Vol. 1. Delhi: Birla Publications Pvt. Ltd.; 2008. p. 69-72.

2. Zhou R, Xu Q, Zheng P, Yan L, Zheng J, Dai G. Cardioprotective effect of fluvastatin on isoproterenol-induced myocardial infarction in rat. Eur J Pharmacol 2008;586:244-50.

3. Rajadurai M, Prince PS. Preventive effect of naringin on lipid peroxides and antioxidants in isoproterenol-induced cardiotoxicity in Wistar rats: Biochemical and histopathological evidences. Toxicology 2006;228:259-68.

4. Rathore N, John S, Kale M, Bhatnagar D. Lipid peroxidation and antioxidant enzymes in isoproterenol induced oxidative stress in rat tissues. Pharmacol Res 1998;38:297-303.

5. Suchalatha S, Shyamala DC. Protective effect of Terminalia chebula 
against experimental myocardial injury induced by isoproterenol. Indian J Exp Biol 2004;42:174-8.

6. Latha B, Latha MS. Antioxidant and curative effect of Leucas aspera methanolic extract against carbontetra chloride induced acute liver injury in rats. Int J Pharm Pharm Sci 2012;5:374-8.

7. Srinivasahan V, Durairaj B. Antioxidant and free radical scavenging effect of Morinda citrifolia fruit extract. Int J Pharm Pharm Sci 2014;6:55-9.

8. Asuntha G, Prasannaraju Y, Prasad KV. Effect of ethanol extract of Indigofera tinctoria Linn (Fabaceae) on lithium/pilocarpine-induced status epilepticus and oxidative stress in Wistar rats. Trop J Pharm Res 2010;9:149-56.

9. Verma SM, Suresh KB, Amit V. Antidiabetic activity of leaves of Indigofera tinctoria Linn (Fabaceae). Int J Toxicol Pharmacol Res 2010;1:42-3

10. King J. Practical Clinical Enzymology. London: Van Nostrand Co. Ltd.; 1965. p. 121

11. Lowry OH, Rosebrough NJ. Assay for lipid peroxides in animal tissue with thiobarbituric acid reaction. Ann Biochem 1951;195:133-40.

12. Kakkal P, Das B, Viswanatha PN. A modified spectrophotometric of superoxide dismutase. Indian J Biomed Biophysiol 1984;21:131-2.

13. Tietze F. Quantitative determination of Glutathione: Enzymatic method. Anal Chem 1969;27:502-20.

14. Okhawa H, Ohisini N, Yagi K. Reaction of linoleic acid hydroperoxides with tiobarbituric acid. Anal Biochem 1979;95:133.
15. Asdaq SM, Chakraborty M. Myocardial potency of Semecarpus anacardium nut against isoproterenol induced myocardial damage in rat. Int J Pharm Sci Rev Res 2010;2:10-3.

16. Muthu R, Madhesh M, Malaiyandi S, Vaiyapuri M. Cardioprotective effect of black cumin on isoproterenol-induced myocardial infarction in rats. J Pharm Res 2011;4:2040-4.

17. Sasikumar CS, Devii CS. Protective effect of abana, a poly-herbal formulation, on isoproterenol-induced Myocardial infarction in rats. Indian J Pharmacol 2000;32:198-201.

18. Muralidharan P, Balamurugan G, Kumar P. Inotropic and cardioprotective effects of Daucus carota Linn. On isoproterenol- induced myocardi infarction. J Bangladesh Pharmacol Soc 2008;3:74-9.

19. Singh R, Sharma S, Sharma V. Comparative and quantitative analysis of antioxidant and scavenging potential of Indigofera tinctoria Linn. Extracts. J Integr Med 2015;13:269-78.

20. Rajendran R, Suseela L, Sundaram RM, Basha NS. Cardio stimulant activity of bark and wood of Premna serratifolia. J Bangladesh Pharmacol Soc 2008;3:107-13.

21. Mohanty IR, Arya DS, Gupta SK. Dietary Curcuma longa protects myocardium against isoproterenol induced hemodynamic, biochemical and histopathological alternations in rats. Int J Appl Res Nat Prod 2009;1:19-28.

22. Murugesan M, Revathi R, Manju V. Cardio-protective effect of fenugreek on isoproterenol-induced myocardial infarction in rats. Indian J Pharmacol 2011;43:516-9. 